\title{
Determination of the median nerve safe-zone in the carpal tunnel using the distal forearm bony prominences
}

\author{
N.O. Ajayi, N. Naidoo, L. Lazarus, K.S. Satyapal \\ Department of Clinical Anatomy, School of Laboratory Medicine and Medical Sciences, College of Health Sciences, \\ University of KwaZulu-Natal, Westville Campus, Durban, South Africa
}

[Received 10 December 2013; Accepted 22 January 2014]

Background: The compression of the median nerve (MN) in the carpal tunnel (CT) is one of the most common aetiologies of entrapment neuropathy syndromes in clinical practice. The aim of this study was to investigate the relationship of the palpable bony prominences of the distal forearm (radial styloid process [RSP] and ulnar styloid process [USP]) with MN in the CT, in order to determine a safe-zone of the MN during carpal tunnel procedures.

Materials and methods: This study involved the bilateral dissection of the CT region of 30 adult cadaveric specimens $(n=60)$.

Results: The mean distance between the RSP and USP was $49.34 \mathrm{~mm}$. The mean distance of the MN from the RSP and the USP were $22.44 \mathrm{~mm}$ and $26.66 \mathrm{~mm}$, respectively. The mean diameter of the MN within the CT deep to the flexor retinaculum was $5.93 \mathrm{~mm}$. In addition, the $M N$ was located postero-lateral and postero-medial to palmaris longus tendon (PLT) in $78.33 \%$ and $21.67 \%$ of specimens, respectively.

Conclusions: This study found that the MN was located less than $60 \%$ of the RSP-USP distance from the RSP. Furthermore, the MN was mostly located postero-lateral to the PLT. Therefore, injection or surgical incision made at/medial to a point $60 \%$ of the RSP-USP distance from the RSP will be outside the safe-zone of the MN. The knowledge of this surface anatomical relationship of the MN may be useful during decompression for CT syndrome. (Folia Morphol 2014; 73, 4: 409-413)

Key words: median nerve, ulna styloid process, radial styloid process, carpal tunnel, carpal tunnel syndrome

\section{INTRODUCTION}

The carpal tunnel (CT) is a narrow fibro-osseous tunnel at the wrist through which the flexor tendons and the median nerve (MN) pass into the hand [4]. CT syndrome, which results from an increased pressure in the CT [9], is the most common nerve entrapment syndrome in clinical practice $[2,4,19]$.

The most common surgical hand and wrist procedure is the CT decompression for CT syndrome [14]. Injec- tions into the $C T$ are widely performed during diagnostic and therapeutic procedures in the management of $\mathrm{CT}$ syndrome [5]. A major complication of CT injection is an intraneural injection into or a direct needle injury to the MN $[13,23]$. This accidental injury of the MN is extremely painful and may result in serious and prolonged or even permanent disability of the hand [15].

The prevention of the iatrogenic injury of the $\mathrm{MN}$ depends on the injection or incision in the CT made

Address for correspondence: Prof. K.S. Satyapal, Department of Clinical Anatomy, School of Laboratory Medicine and Medical Sciences, College of Health Sciences, University of KwaZulu-Natal, Private Bag X54001, Durban, 4000, South Africa, tel:+27 312607110 , fax:+27 312607890 , e-mail: satyapalk@ukzn.ac.za 
outside the safe-zone of the MN. However, there is no consensus amongst authors with regard to the safest injection or incision site in the CT [5]. Recently, the use of ultra-sonographic guidance during CT injection or procedure has been advocated in order to minimise possible $\mathrm{MN}$ injury during $\mathrm{CT}$ procedures [20]. The knowledge of the anatomic structures at risk in the $\mathrm{CT}$ and their relationship should decrease the risk of iatrogenic injury [12]. Studies have evaluated the relationship of the structures in the distal forearm such at the flexor tendons and palmaris longus tendon (PLT) to the MN in order to determine a safe-zone for the MN during CT procedures. From the literature reviewed, there is no study on the relationship of the palpable bony landmarks of the distal forearm to the location of the MN in the CT. The aim of this study was to investigate the relationship of the palpable bony prominences of the distal forearm (radial styloid process [RSP] and ulnar styloid process [USP]) to the MN in the CT, in order to determine a safe-zone of the $\mathrm{MN}$ during CT procedures.

\section{MATERIALS AND METHODS}

Thirty ( $n=60$; 30 right; 30 left) adult cadaveric upper limb specimens (with no previous history of trauma, surgery or anomaly to the forearm and hand regions) were obtained from the Department of Clinical Anatomy, School of Laboratory Medicine and Medical Sciences, University of KwaZulu-Natal. The study was conducted in accordance with Chapter 8 of the National Health Act No. 61 of 2003. These specimens consisted of upper limbs of 14 female $(\mathrm{n}=28 ; 14$ right; 14 left $)$ and 16 male $(\mathrm{n}=32 ; 16$ right; 16 left) cadavers. The distal forearm and the wrist of the specimens were dissected. The distance between the RSP and the USP and width of the MN in the CT were measured and recorded. The measurements were taken with an electronic digital microcalliper (Digitronic Calliper; Wilson Wolpart Europe 110/15 DAB; Mastricht Netherlands). The position of the $\mathrm{MN}$ in relation to the PLT was observed and documented. The level of division of the MN in relation to the transverse carpal ligament was also observed and documented. In addition, the distances of the PLT from the RSP and USP were also determined and documented. The mean value of the measurements taken were compared between males and females using Student's t test and a $p$ value $\leq 0.05$ was considered significant.

\section{RESULTS}

The mean distance between the RSP and the USP was $49.34 \mathrm{~mm}$ (40.39-60.38 mm). The mean distance of the MN from the RSP was recorded as $22.44 \mathrm{~mm}$ $(13.73-41.98 \mathrm{~mm})$, while the mean distance of the MN from the USP was $26.66 \mathrm{~mm}(17.57-34.96 \mathrm{~mm})$. The mean distance of the MN to the RSP $(22.44 \mathrm{~mm})$ in the total sample $(n=60)$ was recorded to be less than $50 \%$ of the RSP-USP distance. In $76.7 \%$ (46/60) of specimens, the location of the MN to the RSP was less than $50 \%$ of the RSP-USP distance. The location of the MN to the RSP was between the ranges of $50-59 \%, 60-69 \%$ of the RSP-USP distance in $18.3 \%$ $(11 / 60)$ and $3.3 \%(2 / 60)$ of specimens, respectively. In $1.7 \%(1 / 60)$ of specimens, the location of the MN to the RSP was greater than $70 \%$ of the RSP-USP distance (Fig. 1).

The mean RSP-USP distances were $51.2 \mathrm{~mm}$ and $47.22 \mathrm{~mm}$ in males and females, respectively. The mean distance of the MN from the RSP were recorded as $25 \mathrm{~mm}$ and $23.31 \mathrm{~mm}$ in males and females, respectively, while the mean distance of the MN from the USP in males and females were $23.21 \mathrm{~mm}$ and $21.55 \mathrm{~mm}$, respectively. There was a statistically significant difference in the RSP-USP distance between males and females $(p=0.0004)$. However, there was no statistically significant difference in the RSP-PLT and the RSP-MN distance between males and females, with a $p$ value of 0.24 and 0.20 , respectively (Table 1 ).

The mean diameter of the MN within the CT deep to the flexor retinaculum was $5.93 \mathrm{~mm}(2.51-8 \mathrm{~mm})$. Furthermore, the diameter of the MN was added to the distance of the MN to the RSP, a mean distance of $28.37 \mathrm{~mm}$ was calculated which was $57.5 \%$ of the RSP-USP from the RSP. The MN was observed to divide distal to the flexor retinaculum in $86.67 \%(52 / 60)$ of

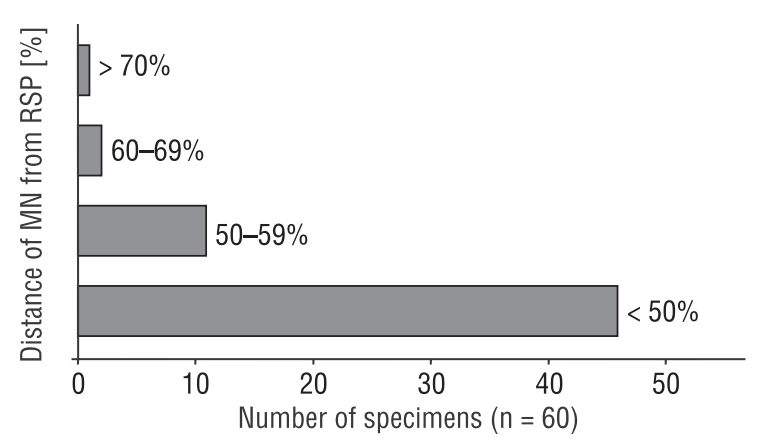

Figure 1. Relative distance of the median nerve (MN) from the radial styloid process (RSP). 
Table 1. Mean diameter of the median nerve (MN) and the distance between the ulna styloid processes (USP), the radial styloid process (RSP) and palmaris longus tendon (PLT), the RSP and the MN in males and females

\begin{tabular}{lccc}
\hline Parameter & Male & Female & P \\
\hline Mean RSP-USP distance [mm] & 51.2 & 47.22 & 0.0004 \\
Mean RSP-PLT distance [mm] & 25 & 23.31 & 0.24 \\
Mean RSP-MN distance [mm] & 23.21 & 21.55 & 0.20 \\
Mean diameter of MN [mm] & 5.74 & 6.17 & 0.09 \\
\hline
\end{tabular}

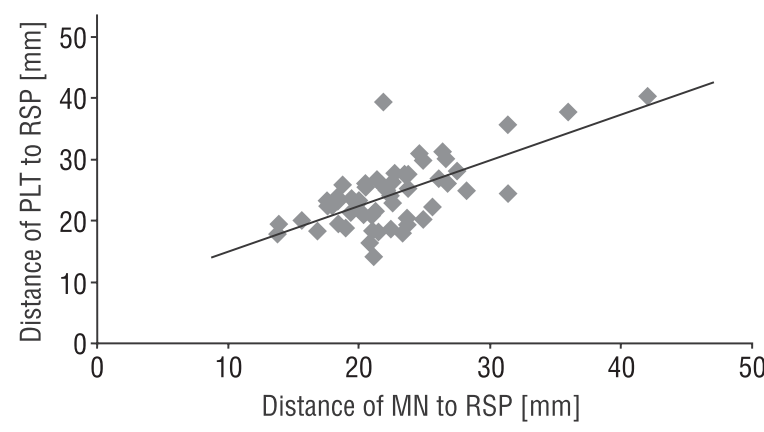

Figure 2. Correlation plot showing the relationship of the median nerve (MN) and the palmaris longus tendon (PLT) in the radial styloid process (RSP).

the specimens, within the CT in $11.67 \%$ (7/60) of the specimens and proximal to the flexor retinaculum in $1.67 \%(1 / 60)$ of the specimens (Fig. 1). The PLT was found in all the specimens dissected. In addition, the location of the MN was observed to be closely related to the position of the PLT in the distal forearm (Fig. 2). There was a positive correlation between the distance of the MN to the RSP and the distance of the PLT to the RSP, with a correlation coefficient ( $r$ ) of 0.66 . The MN was located postero-laterally and postero-medially to the PLT in $78.33 \%(47 / 60)$ and $21.67 \%(13 / 60)$ of the specimens, respectively.

\section{DISCUSSION}

Since the introduction of CT release surgery for the treatment of MN entrapment at the wrist, several other conservative measures have been advocated, including splinting of the wrist and the injection of steroid into the CT [8]. There is no consensus amongst authors with regard to the best injection site in the CT; therefore, there is no definitive technique for optimal placement of steroid injection into the CT [15]. The various recommended sites of injection into the $\mathrm{CT}$ include: midway between the PLT and the flexor carpi ulnaris (FCU) tendon [3, 7], just medial to the PLT $[13,22]$, between PLT and flexor carpi radialis (FCR) tendon [8, 11], just medial to the FCR tendon [10] and through the FCR tendon [5] (Table 2).

In our study, the mean distance of $49.33 \mathrm{~mm}$ was recorded between the RSP and the USP. There was a significant difference in the RSP-USP distance between males and females $(p=0.0004)$, which indicated that males were shown to have larger RSP-USP distance than females. The mean distance $(22.6 \mathrm{~mm}$ ) of the MN from the RSP was less than $50 \%$ of the mean RSP-USP distance in the total sample series. In $76.7 \%(46 / 60)$ of the specimens, the MN was located less than $50 \%$ of the RSP-USP distance from the RSP. Although, the MN was found greater than $60 \%$ of the distance from RSP in 5\% (3/60) of the specimens (Fig. 1), in these specimens, the PLT was found closely related to the MN (Fig. 2). The distance of the MN to the RSP positively correlated with the distance of the PLT to the RSP $(r=0.66)$ in all the specimens. Therefore, when there is a shift of the MN outside $50 \%$ of the distance from the RSP, the PLT may be used as an anatomical guide in determining the probable location of the MN. Furthermore, with the MN located more postero-lateral to the PLT, it could be deduced from our data that the MN was mostly located in the lateral region of the $\mathrm{CT}$.

Table 2. Various recommended sites of injection into the carpal tunnel

\begin{tabular}{lc}
\hline Authors (year) & Recommendation \\
\hline Federick et al. (1992), Burke et al. (2003) & Midway between the PLT and FCU tendon \\
McConnell and Bush (1990), Stephen et al. (2003) & Just ulnar to PLT \\
Gelberman et al. (1980), Koo and Szabo (2004) & Between PLT and FCR tendons \\
Graham et al. (2004) & Just ulnar to FCR tendon \\
Dubert and Racasan (2006) & Through FCR tendon \\
Current study & Point $60 \%$ medial to RSP \\
\hline
\end{tabular}

FCU — flexor carpi ulnaris; FCR — flexor carpi radialis; PLT — palmaris longus tendon; RSP — radial styloid process 


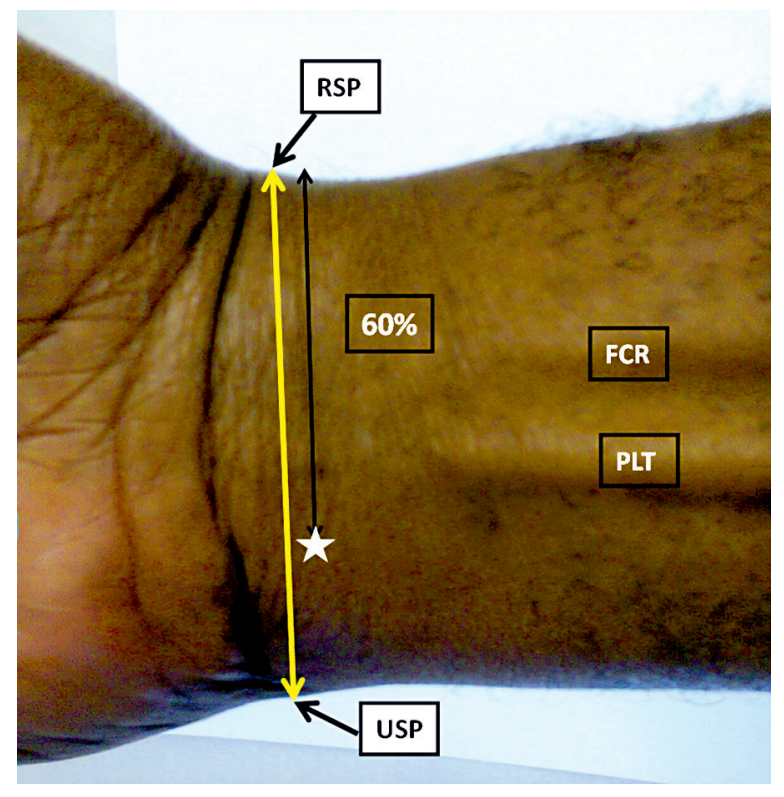

Figure 3. Injection site outside the safe-zone of the median nerve (white star-safe injection point); RSP — radial styloid process; PLT — palmaris longus tendon; FCR — flexor carpi radialis; USP — ulna styloid process.

The mean diameter $(5.93 \mathrm{~mm})$ of the $\mathrm{MN}$ recorded in our study corroborated the earlier report of $6 \mathrm{~mm}$ [6]. The addition of the diameter of the MN to the distance of the MN to the RSP gave a mean distance of $28.37 \mathrm{~mm}$, which was $57.5 \%$ of the RSP-USP distance from the RSP. From our findings, an injection placed or an incision made at a point located at $60 \%$ of the distance between the RSP and USP from the RSP (or medial to this point) will be outside the safe-zone of the MN (Fig. 3). Consequently, our study agrees with authors $[3,7]$ that have suggested injecting the CT between the PLT and the FCU tendon (medial to the PLT) as the MN was more postero-laterally located to the PLT $(78.33 \%)$. The findings in our study indicated that injection given/incision made lateral to the PLT is more likely to injure the MN than when medially placed.

As noted earlier, several authors used the PLT as a landmark in determining the site of injection into the CT. However, the PLT has been reported to be absent in $3.7-50.8 \%$ of individuals $[1,6,16-18]$, and in such cases, using the PLT as a landmark will be impossible. This problem can be circumvented by using the distal forearm bony prominences (RSP and USP) as anatomical landmarks for determining the position of the MN, as suggested by our study. Therefore, the determination of the relationship of the
$\mathrm{MN}$ to the distal forearm bony prominences may be helpful during CT procedures. These bony landmarks may also be useful when there is severe oedema of the distal forearm and wrist with associated difficulty in palpating the PLT.

\section{CONCLUSIONS}

A core clinical skill is the ability to use palpable surface features such as bony prominences and tendons to locate structures under the skin [21]. Injection or surgical incision made medial to $60 \%$ of the distance from the RSP will be outside the safe-zone of the MN. The knowledge of this surface anatomical relationship of the MN with the distal forearm bony prominences may be useful during decompression for CT syndrome.

\section{REFERENCES}

1. Abdel Raouf H, Abdel Kader G, Jaradat A, Dharap A, Fadel R, Salem A (2013) Frequency of palmaris longus absence and its association with other anatomical variations in the Egyptian population. Clin Anat, 26: 572-577.

2. Atroshi I, Gummesson C, Johnsson R, Ornstein E, Ranstam J, Rosén I (1999) Prevalence of Carpal tunnel syndrome in a general population. JAMA, 281: 153-158.

3. Burke FD, Ellis J, McKenna H, Bradley MJ (2003) Primary care management of carpal tunnel syndrome. Postgrad Med J, 79: 433-437.

4. Demircay E, Civelek E, Cansever T, Kabatas S, Yllmaz C (2011) Anatomic variations of the median nerve in the carpal tunnel: a brief review of the literature. Turkish Neurosurgery, 21: 388-396.

5. Dubert T, Racasan O (2006) A reliable technique for avoiding the median nerve during carpal tunnel injections. Joint Bone Spine, 73: 77-79.

6. Eric M, Koprivcic I, Vucinic N, Radic R, Krivokuca D, Leksan I, Selthofer R (2011) Prevalence of the palmaris longus in relation to the hand. Dominance Surg Radiol Anat, 33: 481-484.

7. Frederick HA, Carter PR, Littler JW (1992) Injection injuries to the median and ulnar nerves at the wrist. J Hand Surg, 17: 645-647.

8. Gelberman RH, Aronson D, Weiman MH (1980) Carpal tunnel syndrome. J Bone Joint Surg, 62: 1181-1184.

9. Gelberman RH, Hergenroeder PT, Hargens AR, Lundborg GN, Akeson WH (1981) The carpal tunnel syndrome. A study of carpal canal pressures. J Bone Joint Surg Am, 63: 380-383.

10. Graham RG, Hudson DA, Solomons M, Singer M (2004) A prospective study to assess the outcome of steroid injections and wrist splinting for the treatment of carpal tunnel syndrome. Plast Reconstr Surg, 113: 550-556.

11. Koo JT, Szabo RM (2004. Compression neuropathies of the median nerve. J Am Soc Surg Hand, 4: 156-175.

12. Madhav TJ, To P, Stern PJ (2009) The palmar fat pad is a reliable intraoperative landmark during carpal tunnel release. J Hand Surg; 34A: 1204-1209.

13. McConnell JR, Bush DC (1990) Intraneural steroid injection as a complication in the management of carpal tunnel syndrome. Clin Orthop, 250: 181-184. 
14. Ozcanli H, Coskun HK, Cengiz M, Oguz N, Sindel M (2010) Definition of a safe-zone in open carpal tunnel surgery: a cadaver study. Surg Radiol Anat, 32: 203-206.

15. Racasan O, Dubert T (2005) The safest location for steroid injection in the treatment of carpal tunnel syndrome. J Hand Surg Br, 30: 412.

16. Roohi SA, Choon-Sian L, Shalimar A, Tan GH, Naicker AS (2007) A study on the absence of palmaris longus in a multiracial population. Malaysian Orthopaedic J, 1: 26-28.

17. Sater MS, Dharap AS, Abu-Hijleh MF (2010) The prevalence of absence of the palmaris longus muscle in the Bahraini population. Clin Anat, 23: 956-961.

18. Sebastin SJ, Lim AY, Wong HB (2006) Clinical assessment of absence of the palmaris longus and its association with other anatomical anomalies: a Chinese population study. Ann Acad Med Singapore, 35: 249-253.
19. Skie M, Zeiss J, Ebraheim NA, Jackson WT (1990) Carpal tunnel changes and median nerve compression during wrist flexion and extension seen by magnetic resonance imaging. J Hand Surg, 315A: 934-939.

20. Smith J, Wisniewski SJ, Finnoff JT, Payne JM (2008) Sonographically guided carpal tunnel injections: the ulnar approach. J Ultrasound Med, 27: 1485-1490.

21. Standring S (2012) Evidence-based surface anatomy. Clin Anat, 25: 813-815.

22. Stephen EE, McCabe SJ, Breidenbach WC, LaJoie AS, Abell TD (2003) Predicting the outcome of carpal tunnel release. J Hand Surg, 28: 255-261.

23. Tavares SP, Giddins GES (1996) Nerve injury following steroid injection for carpal tunnel syndrome: a report of two cases. J Hand Surg Br, 21: 208-209. 